\title{
Effectiveness of Mesenchymal Stem Cells and Bovine Colostrum on Decreasing Tumor Necrosis Factor-A Levels and Enhancement of Macrophages M2 in Remnant Liver
}

\author{
Ezra Endria Gunadi* (D), Yan Wisnu Prajoko ${ }^{1}$ (D) Agung Putra ${ }^{2}$ (D) \\ ${ }^{1}$ Department of Biomedical, Faculty of Medicine, Diponegoro University, Semarang, Indonesia; ${ }^{2}$ Stem Cells and Cancer \\ Research, Faculty of Medicine, Sultan Agung Islamic University, Semarang, Indonesia
}

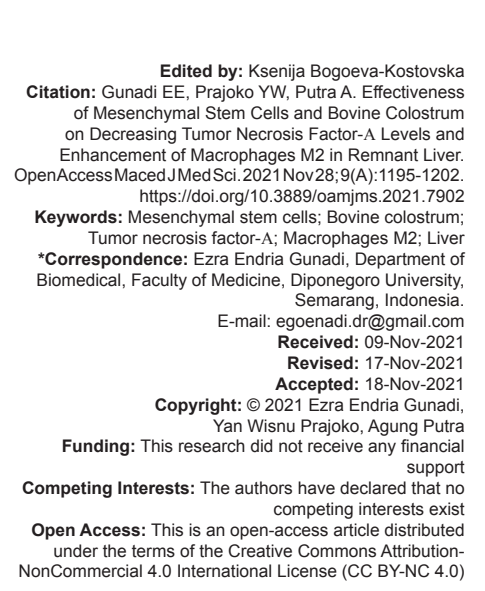

\begin{abstract}
BACKGROUND: Mesenchymal stem cells (MSCs) and bovine colostrum are potential therapies for the treatment of various degenerative and immune diseases.

AIM: This study aimed to analyze the effect of MSCs on levels of tumor necrosis factor-A (TNF- $\alpha$ ) and macrophages M2 in the liver fibrosis of Wistar rats after $50 \%$ resection.

METHODS: This study is a quasi-experimental post-test-only control group design to analyze the effect of giving bovine colostrum and MSCs to test animals on the process of regeneration of the remaining $50 \%$ liver with fibrosis. The study was conducted at the Stem Cell and Cancer Research Universitas Sultan Agung. The number of samples used was 40 male Wistar rats. The independent variables included MSC 1.000 .0000 cells and bovine colostrum at a dose of $15 \mu \mathrm{L} / \mathrm{g}$. Dependent variables used were macrophages M2 and levels of TNF- $\alpha$ ELISA.

RESULTS: TNF- $\alpha$ levels on day 3 were $(p=0.001)$, day 7 were $(p=0.01)$, and day 10 were $(p=0.01)$ in liver tissue in various study groups analyzed using ELISA on day three*. The results showed differences which were significant between the control and treatment groups $(p<0.05)$. The expression of CD163 marked brown in liver tissue had more expression than the control group.

CONCLUSION: The combination of MSCs and bovine colostrum can reduce TNF- $\alpha$ levels and significantly increase
\end{abstract} macrophages expression in the liver fibrosis of Wistar rats after $50 \%$ resection on the $3^{\text {rd }}, 7^{\text {th }}$, and $10^{\text {th }}$ days.

\section{Introduction}

Liver fibrosis results from excessive accumulation of extracellular matrix (ECM) in the liver parenchyma in response to chronic liver damage. This damage can result from viral, autoimmune, cholestatic, toxic or metabolic diseases, including nonalcoholic steatohepatitis (NASH) [1]. Tumor necrosis factor- $\alpha(T N F \alpha)$ is an inflammatory cytokine involved in liver inflammation, which-if it occurs continuously, it can cause liver fibrosis. TNF- $\alpha$ mediates hepatocyte apoptosis leading to fibrosis in rat liver [2], [3].

Mesenchymal stem cells (MSCs) have been rapidly investigated as potential therapies for the treatment of various degenerative and immune diseases, mainly because of their potential differentiation and immunoregulatory properties [4], [5]. MSCs in the pathogenesis of liver fibrosis are said to act as immune modulators, namely inhibition of the secretion of TNF- $\alpha$, IFN- $\gamma$, and IL-12 by dendritic cells, thereby reducing the potential pro-inflammatory effect on liver injury [6], [7]. Bone marrow-MSC (BM-MSC) transplantation in rats induced by liver fibrosis showed an improvement in fibrosis as indicated by histopathology; and showed significant changes in the number of macrophages M1 and M2, transplanted rats showed decreased macrophages M1 and increased macrophages M2 which is significant. The results of this study showed that the increase in macrophages M2 correlated with the improvement of liver fibrosis [8]. Fibrosis therapy using MSCs can also be given through the administration of an MSC-derived factor called secretome which functions as a paracrine. Previous studies related to MSCs on liver resection in rats found that a dose of $1,000,000$ had a positive effect on the process of liver regeneration [9].

The rapid advances in pharmacology have led to many advances in the treatment of diseases including liver fibrosis. One of the newest modalities for the treatment of liver fibrosis is bovine colostrum. Bovine colostrum has many advantages that can be utilized but are not widely known by the public.

Bovine colostrum is milk secreted from the mammary glands of female cows produced after calves 
are born and is a rich natural source of macro and micronutrients, immunoglobulins, and peptides with anti-microbial activity and growth factors [10]. Recent studies examining the effects of bovine colostrum administration on liver fibrosis have shown that bovine colostrum at a dose of $15 \mu \mathrm{L} / \mathrm{g}$ for 14 days in rat models, is shown to be able to improve liver fibrosis by up to $55 \%$, decrease expression of TNF- $\alpha$, Acta2, Col1 $\alpha 1$, and Tgf $\beta 1$, as well as decrease serum ALT levels indicating an improvement in liver function. The study also states that bovine colostrum contains antioxidant components, such as superoxide dismutase, glutathione peroxidase (GPx), catalase, Vitamin E, Vitamin $C$ and carotene [11], [12] The mechanism of bovine colostrum in influencing the pathogenesis of liver fibrosis is through the regulation of oxidative stress and stimulation of hepatocyte proliferation through growth factors. Oxidative stress is known to be the main factor that influences the onset of liver fibrosis and changes the mitochondrial permeability of cells, causing apoptosis and necrosis of hepatocytes [12], [13].

The aim of this study was to analyze the effect of administration of bovine colostrum at a dose of $15 \mu \mathrm{L} / \mathrm{g}$ for 10 days and combined with 1,000,000 MSC cells in Wistar rats with $50 \%$ liver remaining with liver fibrosis after resection and administration of $\mathrm{CCl} 4$ for 6 weeks on the liver regeneration process. The parameters used were TNF- $\alpha$ expression and Macrophages M2 examination. In more detail, this study aimed to analyze the effect of giving MSCs on TNF- $\alpha$ levels in the liver fibrosis of Wistar rats after resection $50 \%$, analyze the effect of giving MSCs on Macrophages M2 in the liver fibrosis of Wistar rats after $50 \%$ resection, analyze the effect of giving Colostrum on TNF- $\alpha$ levels in the liver fibrosis of Wistar rats after resection $50 \%$, analyze the effect of giving Colostrum on TNF- $\alpha$ levels to Macrophages M2 in the liver fibrosis of Wistar rats after $50 \%$ resection, and determine whether the combination of MSCs and bovine colostrum can reduce TNF- $\alpha$ levels and increase Macrophages M2 levels in the liver fibrosis of Wistar rats after $50 \%$ resection.

\section{Methods}

This study is a quasi-experimental post-testonly control group design to analyze the effect of giving bovine colostrum and MSCs to test animals on the process of regeneration of the remaining $50 \%$ liver with fibrosis. The research and data collection was carried out during August - September 2021. The process of administering fibrosis agents, liver resection, feeding according to treatment, and termination of rats was carried out at the Stem Cell and Cancer Research (SCCR) Universitas Sultan Agung, Semarang. Macrophages M2 examination and TNF- $\alpha$ examination were also carried out at the same place.

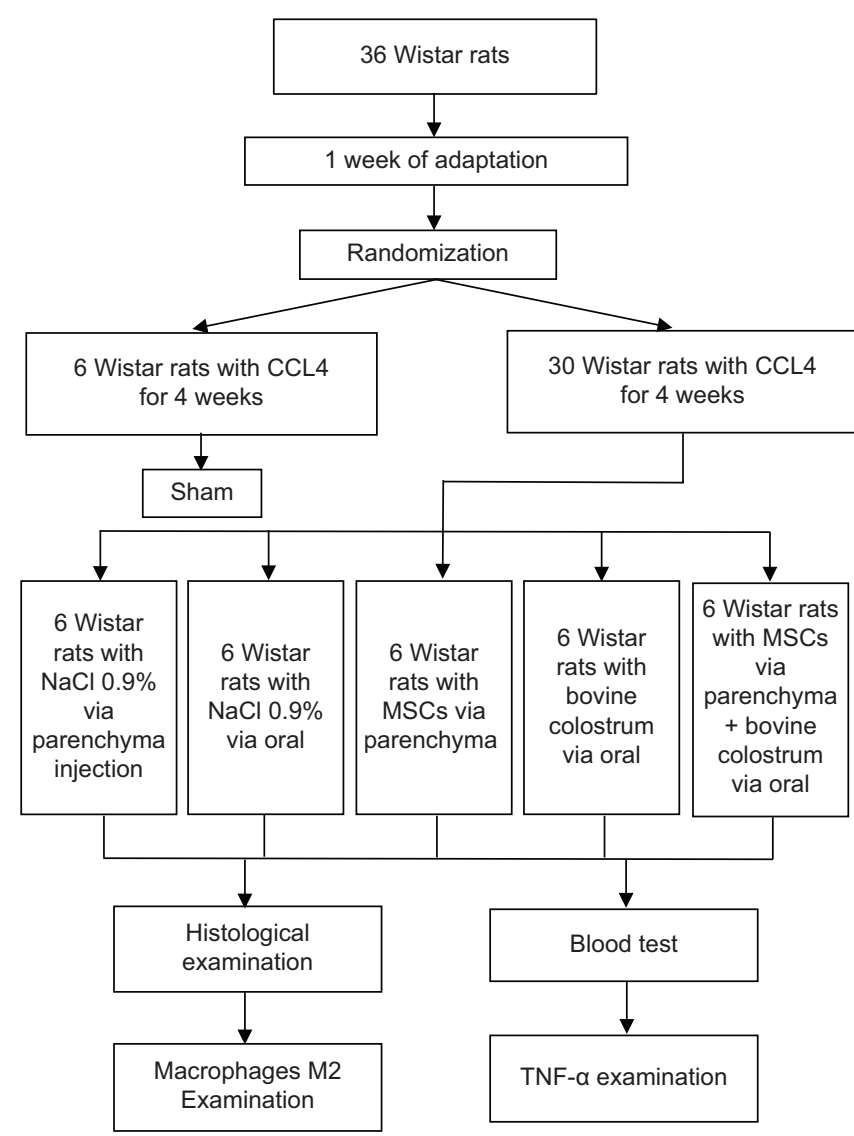

Figure 1: Research flow

The minimum sample used according to the Institutional Animal Care and Use Committee Guidebook and the World Health Organization was at least 5 animals per group adhering to the Replacement, Reduction, and Refinement principle. Referring to this, the number of samples used was 30 male Wistar rats, with 5 rats in each treatment group. To anticipate the exclusion of rats due to dropout criteria, then in each treatment group $10 \%$ of the total sample (1 rat) would be added. Thus, the total sample was 40 rats (Figure 1 ).

\section{Inclusion criteria}

Wistar purebred male rats, 5 months old, weight 200-250 g, healthy and active.

\section{Exclusion criteria}

Wistar rats with anatomical defects.

\section{Dropout criteria}

Rats died during the study and after the treatment, had an infection after surgery.

The variables in this study included Independent variable which consisted MSC 1.000 .0000 cells and bovine colostrum at a dose of $15 \mu \mathrm{L} / \mathrm{g}$; and Dependent variables which consisted macrophages M2 and levels of TNF- $\alpha$ ELISA. 
The materials used in this study were liver biopsies from Wistar rats, bovine colostrum, MSCs, $\mathrm{NaCl}$, rat feed, aquades, ketamine hydrochloride anesthetic, formaldehyde buffer (BNF), alcohol, xylol, paraffin block, liquid paraffin (histoplast), polylysine and oil immersion. The tools used in this study were micropipette, tip (blue tip, yellow tip, pink tip), pippete filler, $15 \mathrm{~mL}$ and $50 \mathrm{~mL}$ conical tube, $1 \mathrm{~mL}$ cryotube, haemocytometer, inverted microscope, $\mathrm{CO}_{2}$ cylinder, scissor, tweezers, scalpel, bistouri, syringes of various sizes, thermostirrer, cold centrifuge (Thermo, USA), minor set, tissue pot, beaker, flask T75 (Corning, Life Sciences, USA), aluminum foil, disk, well plate, 96 well plate, hot plate, hotplate stirrer, disposable pipette, heparin tube (BD Vacutainer, Oxford, UK), conical tune, cryo tube, haemocytometer, cell counter, biosafety cabinet Class 2 (Plymouth, $\mathrm{MN}, \mathrm{US}), \mathrm{CO}_{2}$ incubator (Thermo, USA), sample storage (refrigerator) with temperatures of $20^{\circ} \mathrm{C}$ dan $196^{\circ} \mathrm{C}$, inverted microscope (Carl Zeiss Inc., Gçttingen, Germany), BD Accuri C6 Plus flow cytometer (BD Biosciences, San Jose, CA, USA), immunofluorescence microscope DM IL LED (Leica,Wetzlar, Germany), optilab, decloaking chamber (Biogear), spiner, slide Poly-L-Lysine Coated (Biogear) and microtome (Leica,Wetzlar, Germany).

The implementation of the research was carried out in Hepatic Fibrosis Induction Technique with $\mathrm{CCl}$, Partial Hepatectomy Procedure, MSCs Isolation Technique from Umbilical Cord, Cell Culture and Cell Harvesting Process.

\section{$\mathrm{CCl} 4$}

\section{Hepatic fibrosis induction technique with}

Liver fibrosis was induced by administering $\mathrm{CCl} 4$ at a dose of $0.1 \mathrm{cc} / 100 \mathrm{~g}$ in the first 2 weeks, given every Wednesday and Saturday. For the next 4 weeks, the dose was reduced to $0.05 \mathrm{cc} / 100 \mathrm{~g}$ given every Wednesday and Saturday.

\section{Partial hepatectomy procedure}

In the study, resection of a 2/3 healthy liver would activate progenitor cells from the liver, thus researchers performed a $50 \%$ resection of the liver in the median lobe and right lateral lobe with fibrosis.

\section{MSCs isolation technique of the umbilical}

cord

The whole process was carried out in a biosafety cabinet class, using high-sterility equipment.

\section{Cell culture}

The culture process was carried out in a tissue petri dish which then incubated at $37^{\circ} \mathrm{C}$ and $\mathrm{CO}_{2} 5 \%$.

\section{Cell harvesting process}

1. Cell harvesting was carried out using the third cell harvest which was transferred to a coverslip

2. Clean the medium container using $1 \mathrm{~mL}$ of phosphate buffered saline (PBS) and $1 \mathrm{~mL}$ of trypsin to separate the medium from the cells

3. Incubate for $3 \mathrm{~min}$ at $37^{\circ} \mathrm{C}$

4. Look at the microscope to make sure the cells are loose (released)

5. If they are loose, take trypsin and PBS using a micropipette

6. After that, replace with a complete medium

\section{Results}

\section{MSCs morphology and validation}

MSCs isolation was carried out at the SCCR Laboratory, Faculty of Medicine, Universitas Islam Sultan Agung, Semarang, with a high sterilization rate in a class 2 biosafety cabinet. The population used in this study was the $4^{\text {th }}$ harvest MSCs with morphological characteristics resembling fibroblast cells and attached to a plastic culture base as shown in Figure 2.

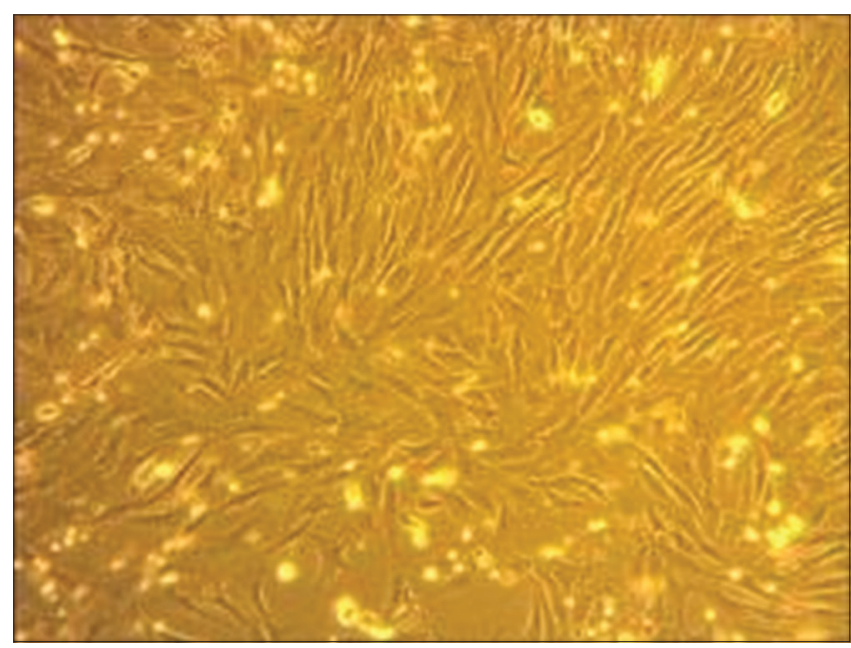

Figure 2: Mesenchymal stem cells morphology with confluent

The obtained MSC cells were then validated using flow cytometry to show that MSCs were able to express surface markers as markers that MSC were in accordance with applicable international standards. The results are as shown in Figure 3.

Differentiation test was performed by induction of osteogenic medium on MSC culture which was then stained with alizarin Red. The results of the differentiation test showed that MSCs were differentiated to become osteogenic with the accumulation of a red color which indicated an accumulation of calcium (Figure 4). 


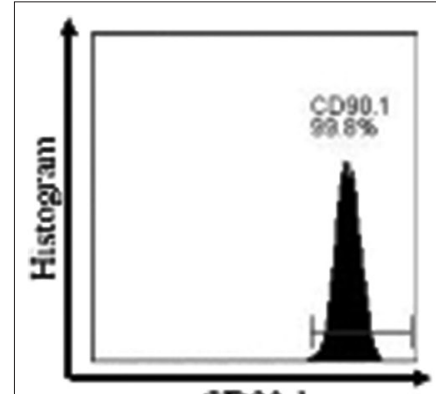

CD90.1

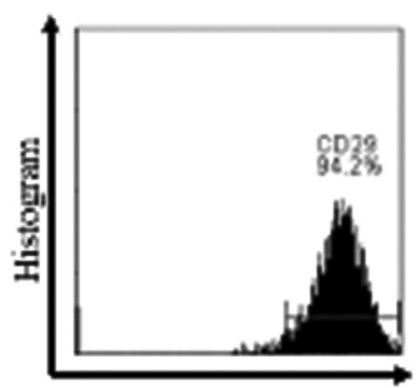

CD29

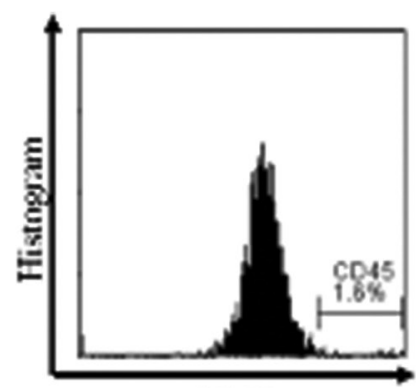

CD45

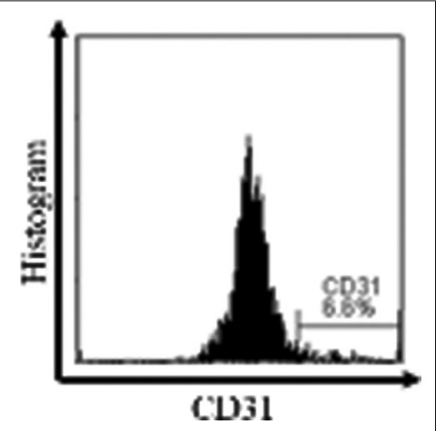

Figure 3: Flow cytometry analysis of CD90, CD29, CD45 and CD31 expression

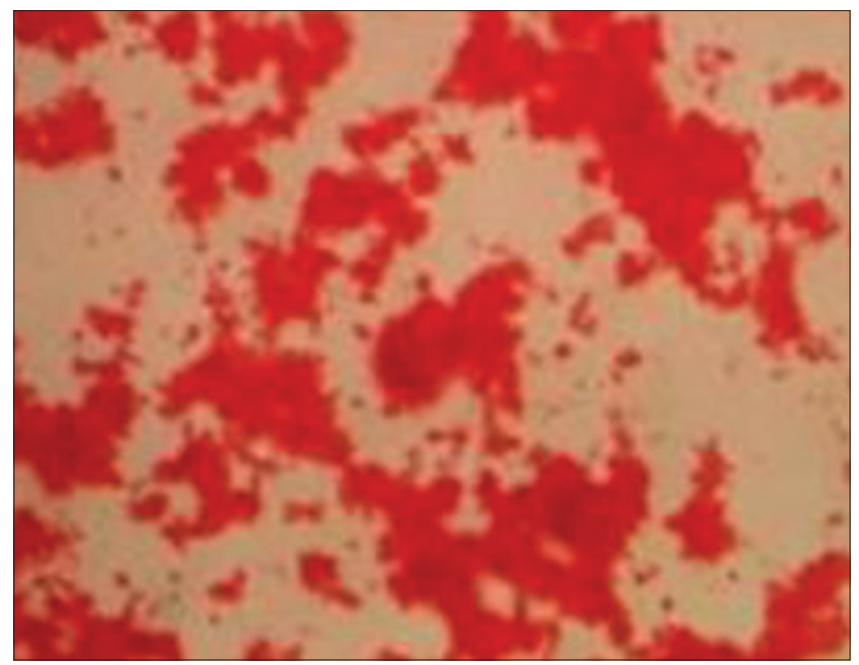

Figure 4: Osteogenic differentiation test

\section{Test animals with liver fibrosis model}

In this study, animal models of liver fibrosis were created by injecting $\mathrm{CCl} 4$ intraperitoneally at a dose of 2 $\mu \mathrm{L} / \mathrm{g}$ twice weekly for 7 weeks. After 7 weeks, the rats were induced by $\mathrm{CCl} 4$; the rats were then validated of fibrosis with termination to ensure that the subject rats used had liver fibrosis. The results of staining using Sirius red showed that the subject had developed fibrosis which was marked in red in the interstitial zone as shown in Figure 5.

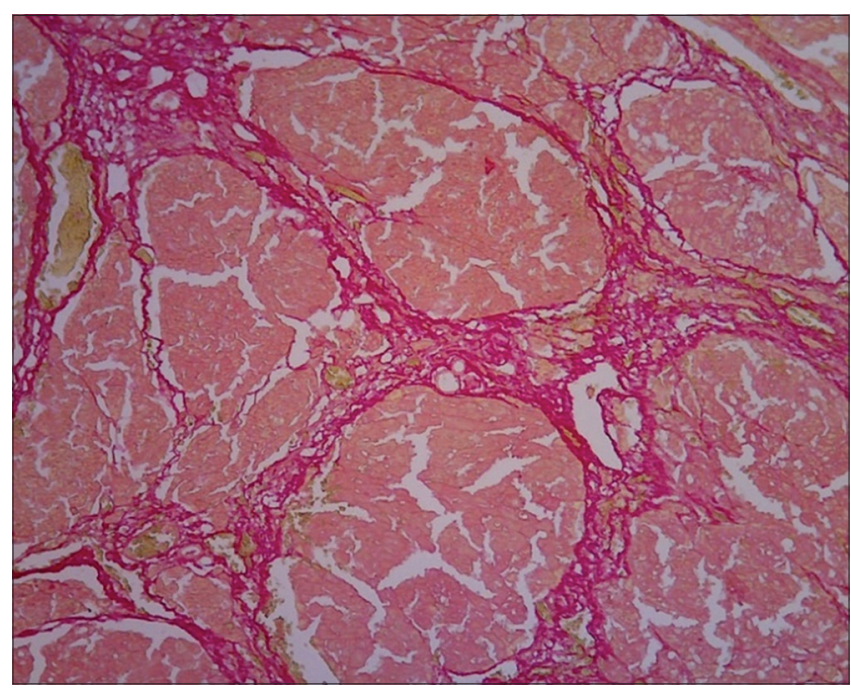

Figure 5: Histological features of liver fibrosis
Differences in TNF- $\alpha$ levels in the MSCs treatment and the MSCs and colostrum combination groups compared to the control group on the $3^{\text {rd }}, 7^{\text {th }}$, and $10^{\text {th }}$ days of liver fibrosis model rats

In the condition of liver fibrosis induced by $\mathrm{CCl} 4$, occurred a series of inflammatory processes that cannot be compensated by the liver cells which caused the formation of fibrotic tissue. This is due to overproduction of ECM by activated myofibroblast cells. In this study, it was obtained results on the levels of TNF- $\alpha$ serum of fibrous model rats that received liver resection on the $3^{\text {rd }}$ day after MSCs and colostrum administration.

Figure 6 above shows the results of the lowest TNF- $\alpha$ level examination in the MSCs group. TNF- $\alpha$ descriptive data of each group were tested for normality using Shapiro-Wilk and homogeneity using Levene's test. The results of the normality and homogeneity tests obtained a significance value for all groups ( $p>0.05$ ). These results indicated that the data were normally distributed so that one-way ANOVA parametric test could be performed and continued with the LSD Posthoc test. In the table above, the results showed that there were significant differences between the MSCs

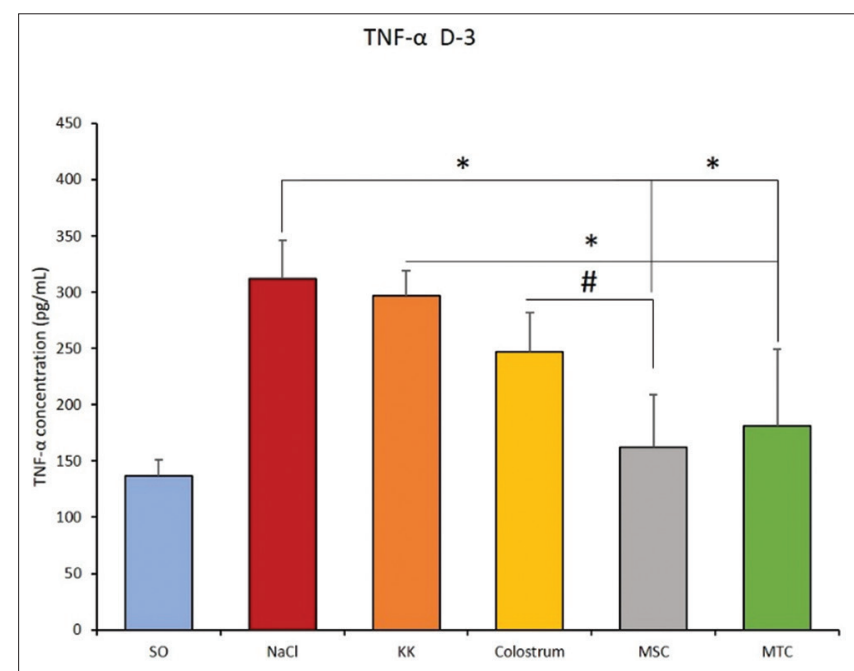

Figure 6: Graph of tumor necrosis factor-A levels on the third day in liver tissue in various study groups analyzed using ELISA on the third day. ${ }^{*}$ This shows a significant difference between the control and treatment groups $(p<0.05)$, while \# shows a significant difference between treatment groups $(p<0.05)$ 
and MSCs and Colostrum Combination treatment groups compared to the control group ( $p<0.05$ ), but in the colostrum treatment itself there was no significant difference compared to the control group ( $p>0.05$ ). The post-hoc test showed a significant difference in the colostrum group and the MSCs group ( $p<0.05)$.

On the $7^{\text {th }}$ day, it was obtained the results of TNF- $\alpha$ levels which were relatively the same, namely there was a significant difference between the MSCs and MSCs and colostrum combination treatment groups compared to the control group ( $p<0.05)$, but in the colostrum treatment itself there was no significant difference compared to the control group ( $p>0.05$ ). The post-hoc test showed no significant difference in the colostrum group and the MSCs group ( $p>0.05)$ as shown in Figure 7.

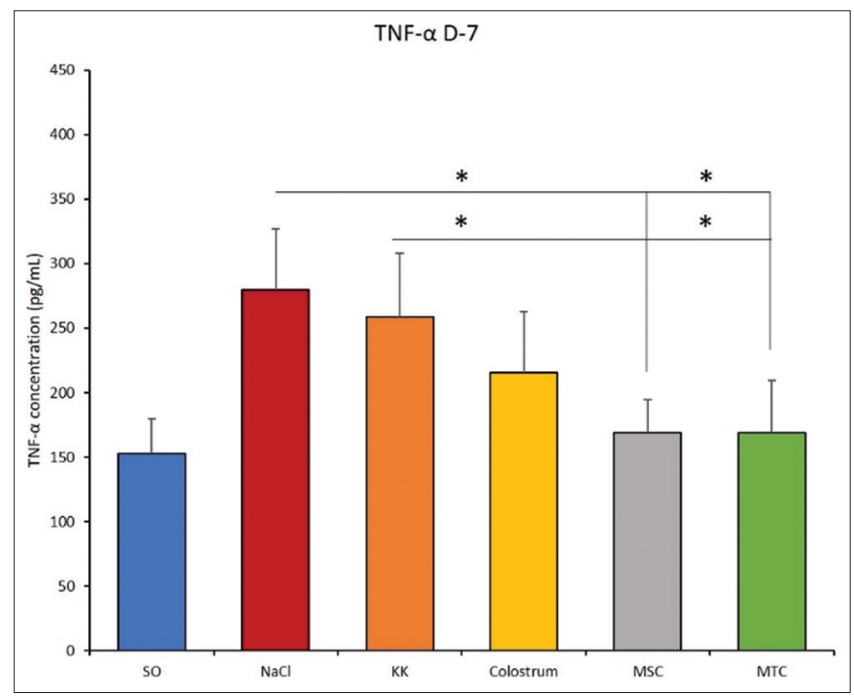

Figure 7: Graph of tumor necrosis factor-A levels in serum on the seventh day in various study groups analyzed using ELISA on the seventh day. ${ }^{*}$ This shows a significant difference between control and treatment groups $(p<0.05)$, while \# shows a significant difference significant between treatment groups $(p<0.05)$

On the $10^{\text {th }}$ day, it was obtained the results of TNF- $\alpha$ levels which were relatively the same, namely there was a significant difference between the MSCs and MSCs and Colostrum Combination treatment groups compared to the control group ( $p<0.05)$, but in the colostrum treatment itself, there was no significant difference compared to the control group ( $p>0.05$ ). The post-hoc test showed that there were significant differences in the colostrum and MSCs groups, as well as the colostrum and MSCs and Colostrum Combination groups $(p<0.05)$ as shown in the following figure (Figure 8).

\section{Differences in CD163 expression in liver tissue of MSCs and MSCs and colostrum combination treatment groups compared to control group on liver fibrosis model rats on the $10^{\text {th }}$ day}

The condition of liver fibrosis induced by $\mathrm{CCl} 4$ involves a variety of cells, including macrophages. In

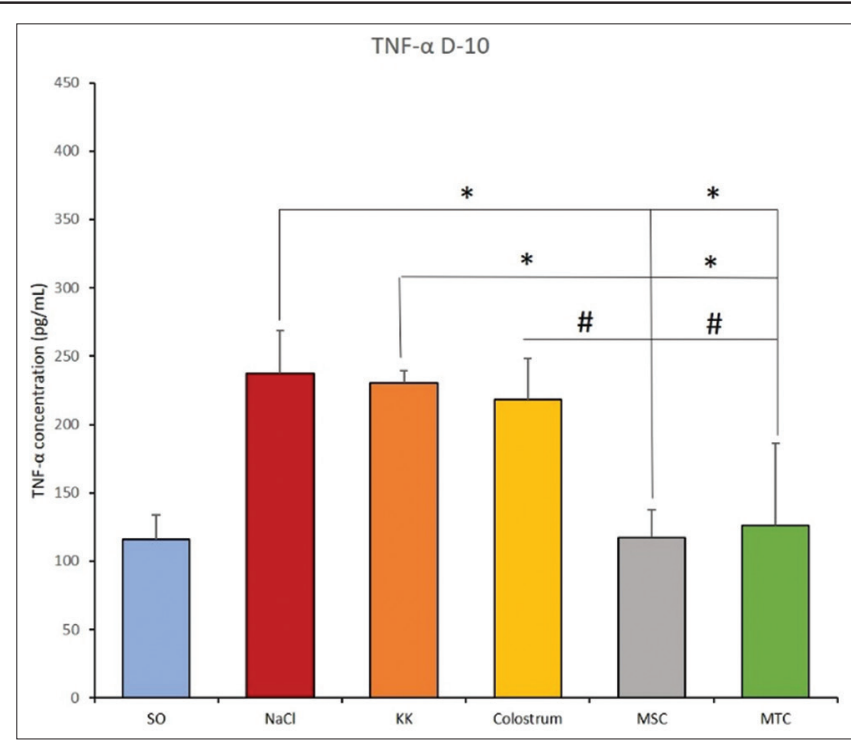

Figure 8: Graph of tumor necrosis factor-A levels in serum on the tenth day in various study groups analyzed using ELISA on the tenth day. ${ }^{*}$ This shows a significant difference between the control and treatment groups $(p<0.05)$, while \# showed a significant difference between treatment groups $(p<0.05)$

this study, examination of type 2 macrophages that act as an anti-inflammatory in liver tissue was carried out. The marker used in this study was CD163 with immunohistochemical technique. From the data obtained, it was found that the expression of CD163 marked brown in liver tissue had more expression than the control group as shown in the arrow in the following image (Figure 9).

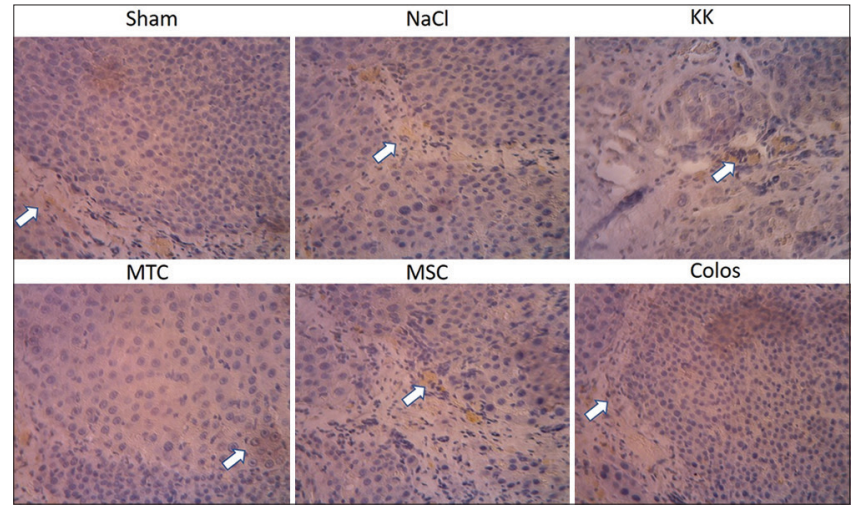

Figure 9: The expression of CD163 in liver tissue in various study groups using immunohistochemical methods at 400x magnification. CD163 expression is shown in brown as in the arrow. In the treatment group, the expression of CD163 was found to be higher than the control group

\section{Discussion}

Liver fibrosis is a response caused by chronic liver injury due to various factors, such as alcohol consumption, NASH, viral hepatitis (hepatitis B [HBV] and hepatitis $\mathrm{C}$ ), autoimmune hepatitis, non-alcoholic 
fatty liver disease and cholestatic liver disease. The general effect of all these factors on the liver is chronic inflammation that results in an abnormal wound healing response. Different cell types and mediators participate in the injury process. The fibrotic response in the liver results in the accumulation of ECM leading to fibrosis formation [14], [15].

TNF is a pleiotropic cytokine, mainly produced by monocytes and macrophages and involved in several physiological and pathological conditions. TNF is classified into two forms: TNF- $\alpha$ (cachectin), which is synthesized by T cells, mast cells, monocytes, macrophages, Kupffer cells, and astrocytes; and TNF- $\beta$, which is synthesized by lymphocytes and natural killer cells, hence it is also called lymphotoxin [16].

In the process of hepatic fibrosis, TNF- $\alpha$ signaling occurs through several mechanisms, namely: pathways of TACE, where TACE will convert TNF- $\alpha$ into a more soluble form; macrophages $\mathrm{M} 1$ in the acute phase of inflammation; and TNF receptors, namely TNFR1 and TNFR2 [5]. HSCs can be activated by stimulation of proinflammatory and fibrogenic cytokines. The contribution of TNF- $\alpha$ in HSCs activation and liver fibrosis has been reported in several studies. TNF- $\alpha$ also affects HSCs survival, increases pro-inflammatory activity of hepatic dendritic cells and induces hepatocyte apoptosis in chronic inflammation. Studies show that TNF- $\alpha$ levels show a significant increase in individuals with liver cirrhosis [2], [16].

Macrophages are little populaces of leukocytes that play an imperative part within the cross-talk between intrinsic and versatile insusceptibility. Macrophages can be categorized as classically actuated macrophages (macrophages M1) or as on the other hand enacted macrophages (M2). Macrophages of this subtype vary in their expression of cell surface markers, generation of particular components and natural movement. Both Macrophages M1 and M2 have been detailed to contribute to the liver fibrosis prepare [17], [18].

Cell therapy and, particularly, MSCs, provide a promising strategy for the management of liver fibrosis. This is due to the ability of MSCs to: (1) enhance the hepatic inflammatory microenvironment; (2) inhibit HSCs activation or induce apoptosis; (3) replace damaged hepatocytes; and (4) promote regeneration of hepatocytes.

MSCs are spindle-shaped fibroblast cells that have the ability to self-renewal. MSCs are known to secrete several substances such as hepatocyte growth factor (HGF) which will initiate the differentiation of MSCs into hepatocyte like cells [19]. Compared with embryonic stem cells, MSCs do not cause ethical problems and have a safer profile in terms of oncogenicity. In particular, in vitro models have provided evidence of the differentiation potential of MSCs into hepatocyte like cells. In addition, in vivo differentiation of hepatic MSCs has been demonstrated in rats, sheep and humans [6].

\section{Effect of MSCs and bovine colostrum on the process of liver fibrosis}

\author{
Effect of MSCs and bovine colostrum on \\ $T N F-\alpha$
}

TNF- $\alpha$ plays an important role in the pathogenesis of liver fibrosis which has been proven in studies that found significantly high serum TNF- $\alpha$ expression in patients with liver cirrhosis and high TNF- $\alpha$ expression was positively correlated with the severity of liver dysfunction [2].

MSCs are potentially relevant therapeutic agents for the treatment of liver disease due to their potential to differentiate into hepatocyte like cells with their properties to modulate immune cells and trigger hepatocyte cell regeneration, as well as ability to produce trophic factors and antioxidant effects. MSCs in the pathogenesis of liver fibrosis are said to act as immune modulators, namely inhibition of the secretion of TNF- $\alpha$, IFN- $\gamma$, and IL-12 by dendritic cells, thereby reducing the potential pro-inflammatory effect on liver injury [6], [20].

A recent study examining the effects of bovine colostrum administration on liver fibrosis showed that bovine colostrum administration reduced the expression of TNF- $\alpha$ in test animals. Studies provide that Bovine colostrum at a dose of $15 \mu \mathrm{L} / \mathrm{g}$ for 14 days in rat models and are shown to be able to improve liver fibrosis by up to $55 \%$, decrease expression of TNF- $\alpha$, Acta2, Col1 $\alpha 1$, and Tgf $\beta 1$, as well as decrease serum ALT levels indicating an improvement in liver function. The study also states that bovine colostrum contains antioxidant components, such as superoxide dismutase, GPx, catalase, Vitamin E, Vitamin C and carotene [11]. The mechanism of bovine colostrum in influencing the pathogenesis of liver fibrosis is through the regulation of oxidative stress and stimulation of hepatocyte proliferation through growth factors. Oxidative stress is known to be the main factor that influences the onset of liver fibrosis and changes the mitochondrial permeability of cells, causing apoptosis and necrosis of hepatocytes [12].

\section{Effect of MSCs and bovine colostrum on macrophages $M 2$}

Macrophages M2 work to create an antiinflammatory environment by producing transforming growth factor- $\beta$ (TGF- $\beta$ ), IL10, arginase, and $\mathrm{HO}-1$, as well as promoting wound healing and regeneration [21]. However, if the injury to liver tissue persists, then macrophages M2 will play an important role in fibrosis formation and express a number of profibrotic factors such as TGF- $\beta$, platelet-derived growth factor (PDGF), vascular endothelial growth factor (VEGF), insulin growth factor (IGF)-1, and Galactin-3 [22].

The role of MSCs in regulating liver fibrosis through macrophages M2 was demonstrated in a study 
on BM-MSC transplantation in rats induced by liver fibrosis; the results showed decrease macrophages M1 value and a significant increase in macrophages M2 that was directly proportional to the degree of liver fibrosis repair. The results of this study showed that the increase in macrophages M2 correlated with the improvement of liver fibrosis [8], [23].

As already described, bovine colostrum mediates liver fibrosis through the regulation of oxidative stress and stimulates of hepatocyte proliferation through growth factors. When there is injury to liver tissue, reactive oxygen species (ROS) formation will occur and macrophages M2 will be induced to the site of injury after the acute phase is complete. The role of colostrum which is to reduce the inflammatory process of the ROS pathway will be in line with the anti-inflammatory properties provided by macrophages M2.

\section{Effect of MSCs and bovine colostrum on liver regeneration}

The liver regeneration process can occur through several different mechanisms, namely: cytokine signaling, growth factor-mediated pathways, metabolic pathways, and through progenitor cells [24].

In the cytokine signaling pathway, after partial hepatectomy of the liver, TNF will bind to TNF-receptors in non-parenchymal cells, especially Kupffer cells. This leads to NFB activation and IL-6 production which is reported to initiate regeneration in hepatocytes.

In the growth factor-mediated pathway, hepatocytes develop through the cell cycle in response to a pool of mitogenic growth factors. This growth factor makes hepatocytes in the G1 cell cycle possible to go directly to the $S$ phase. Epidermal growth factor (EGF) and HGF are the most important growth factors during liver regeneration and can be produced by activated stellate cells after liver resection [25].

In the metabolic pathway, after liver resection, the liver must provide an environment that supports the regeneration process by providing adequate systemic energy requirements needed for DNA replication and cell division. The amino acid regulates hepatocyte proliferation by modulating cyclin D1 expression. Studies in rats have shown that administration of amino acids causes hepatocyte replication, whereas protein restriction inhibits regeneration [26].

Next, liver regeneration process can also happen through liver progenitor cells or the so-called oval cells because its nucleus shape [27], which is mentioned as second line after injury and matured when hepatocytes are unable to proliferate. Oval cells proliferate in the peri-portal area depending on growth factors produced by stellate cells including HGF, fibroblast growth factor (FGF)-1, FGF2, and VEGF. Oval cells are capable of producing albumin and alphafetoprotein, and becoming basophilic hepatocytes within four to five days after activation. Eventually these cells can become mature hepatocytes [24]. It has been reported that at $50 \%$ loss of hepatocytes with decreased proliferation of mature hepatocytes leads to progenitor cell proliferation [28].

Several growth factors found in bovine colostrum are IGF, EGF, TGF- $\alpha$, TGF- $\beta$, PDGF, and VEGF. In addition, the studies reported that IGF-1 reduces the expression of induced nitric oxide synthase which is widely produced in rat models of fibrosis induced by carbon tetrachloride $(\mathrm{CCl} 4)$, thereby reducing the incidence of liver fibrosis through the ROS regulatory pathway [10].

Meanwhile, MSC does not only produce growth factors but also other features namely mitogenic and angiogenesis effects. The growth factors produced are stromal cell-derived factor 1, HGF, IGF-1, and VEGF. The mitogenic effect of MSCs is due to the secretion of EGF, HGF, nerve growth factor, and TGF- $\alpha$, while the effect of angiogenesis is due to VEGF production [7].

Hence, it can be seen that MSCs and bovine colostrum can affect the liver regeneration process through growth factor-mediated pathways-and pathways through hepatic progenitor cells (oval cells).

\section{Conclusion}

MSCs administration could significantly reduce TNF- $\alpha$ levels in the liver fibrosis of Wistar rats after $50 \%$ resection on the $3^{\text {rd }}, 7^{\text {th }}$, and $10^{\text {th }}$ days. MSCs administration could significantly increase the expression of macrophages M2 in the liver fibrosis of Wistar rats after $50 \%$ resection. Bovine colostrum administration can reduce TNF- $\alpha$ levels in the liver fibrosis of Wistar rats after resection by $50 \%$ on the $3^{\text {rd }}, 7^{\text {th }}$, and $10^{\text {th }}$ days but not statistically significant. Bovine colostrum administration can increase the expression of macrophages M2 in the liver fibrosis of Wistar rats after $50 \%$ resection. The MSC and bovine colostrum combination could significantly reduce TNF- $\alpha$ levels in the liver fibrosis of Wistar rats after $50 \%$ resection on the $3^{\text {rd }}, 7^{\text {th }}$, and $10^{\text {th }}$ days.

\section{References}

1. Böttcher K, Pinzani M. Pathophysiology of liver fibrosis and the methodological barriers to the development of anti-fibrogenic agents. Adv Drug Deliv Rev. 2017;121:3-8. https://doi. org/10.1016/j.addr.2017.05.016

PMid:28600202

2. Sabry HS, El-Hendy AA, Mohammed HI, Essa AS, Abdel-Aziz AS. Study of serum tumor necrosis factor- $\alpha$ in patients with liver cirrhosis. Menoufia Med J. 2015;28(2):525.

3. Osawa Y, Kojika E, Hayashi Y, Kimura M, Nishikawa K, 
Yoshio $\mathrm{S}$, et al. Tumor necrosis factor- $\alpha$-mediated hepatocyte apoptosis stimulates fibrosis in the steatotic liver in mice. Hepatol Commun. 2018;2(4):407-20. https://doi.org/10.1002/ hep4.1158

\section{PMid:29619419}

4. Ren G, Chen X, Dong F, Li W, Ren X, Zhang Y, et al. Concise review: Mesenchymal stem cells and translational medicine: Emerging issues. Stem Cells Transl Med. 2012;1(1):51-8. https://doi.org/10.5966/sctm.2011-0019

PMid:23197640

5. Zhao $Q$, Ren $H$, Han Z. Mesenchymal stem cells: Immunomodulatory capability and clinical potential in immune diseases. J Cell Immunother. 2016;2(1):3-20

6. Berardis S, Sattwika PD, Najimi M, Sokal EM. Use of mesenchymal stem cells to treat liver fibrosis: Current situation and future prospects. World J Gastroenterol. 2015;21(3):742-58. https://doi.org/10.3748/wjg.v21.i3.742 PMid:25624709

7. Eom YW, Shim KY, Baik SK. Mesenchymal stem cell therapy for liver fibrosis. The Korean J Intern Med. 2015;30(5):580-9. https://doi.org/10.3904/kjim.2015.30.5.580

PMid:26354051

8. Luo XY, Meng XJ, Cao DC, Wang W, Zhou K, Li L, et al. Transplantation of bone marrow mesenchymal stromal cells attenuates liver fibrosis in mice by regulating macrophage subtypes. Stem Cell Res Ther. 2019;10(1):16. https://doi. org/10.1186/s13287-018-1122-8

PMid:30635047

9. Kim D, Cho GS, Han C, Park DH, Park HK, Woo DH, et al. Current understanding of stem cell and secretome therapies in liver diseases. Tissue Eng Regen Med. 2017;14(6):653-65. https://doi.org/10.1007/s13770-017-0093-7 PMid:30603518

10. Playford RJ, Weiser MJ. Bovine colostrum: Its constituents and uses. Nutrients. 2021;13(1):265. https://doi.org/10.3390/ nu13010265

\section{PMid:33477653}

11. Sinn DH, Gwak GY, Kwon YJ, Paik SW. Anti-fibrotic effect of bovine colostrum in carbon tetrachloride-induced hepatic fibrosis. Precis Future Med. 2017;1(2):88-94.

12. Peverill W, Powell LW, Skoien R. Evolving concepts in the pathogenesis of NASH: Beyond steatosis and inflammation. Int J Mol Sci. 2014;15(5):8591-638. https://doi.org/10.3390/ ijms15058591

PMid:24830559

13. Shimamoto $\mathrm{K}$, Hayashi $\mathrm{H}$, Taniai $\mathrm{E}$, Morita $\mathrm{R}$, Imaoka M, Ishii $\mathrm{Y}$, et al. Antioxidant $\mathrm{N}$-acetyl-L-cysteine (NAC) supplementation reduces reactive oxygen species (ROS)-mediated hepatocellular tumor promotion of indole-3-carbinol (I3C) in rats. J Toxicol Sci. 2011;36(6):775-86. https://doi.org/10.2131/jts.36.775 PMid:22129741

14. Sun M, Kisseleva T. Reversibility of liver fibrosis. Clin Res Hepatol Gastroenterol. 2015;39 Suppl 1:S60-3. https://doi. org/10.1016/j.clinre.2015.06.015 PMid:26206574

15. Pellicoro A, Ramachandran P, Iredale JP. Reversibility of liver fibrosis. Fibrogenesis Tissue Repair. 2012;5 Suppl 1:S26. https://doi.org/10.1186/1755-1536-5-S1-S26 PMid:23259590

16. Yang YM, Seki E. TNF $\alpha$ in liver fibrosis. Curr Pathobiol Rep. 2015;3(4):253-61. https://doi.org/10.1007/ s40139-015-0093-z

\section{PMid:26726307}

17. Zhang L, Wang $\mathrm{Y}$, Wu G, Xiong W, Gu W, Wang CY Macrophages: Friend or foe in idiopathic pulmonary fibrosis? Respir Res. 2018;19(1):170

18. Navegantes KC, de Souza Gomes R, Pereira PA, Czaikoski PG, Azevedo $\mathrm{CH}$, Monteiro MC. Immune modulation of some autoimmune diseases: The critical role of macrophages and neutrophils in the innate and adaptive immunity. J Transl Med. 2017;15(1):36. https://doi.org/10.1186/s12967-017-1141-8 PMid:28202039

19. Berardis S, Lombard C, Evraerts J, El Taghdouini A, Rosseels V, Sancho-Bru P, et al. Gene expression profiling and secretome analysis differentiate adult-derived human liver stem/progenitor cells and human hepatic stellate cells. PLoS One. 2014;9(1):e86137. https://doi.org/10.1371/journal. pone.0086137 PMid:24516514

20. Lee CA, Sinha S, Fitzpatrick E, Dhawan A. Hepatocyte transplantation and advancements in alternative cell sources for liver-based regenerative medicine. J Mol Med. 2018;96(6):469-81. https://doi.org/10.1007/s00109-018-1638-5 PMid:29691598

21. Rengasamy M, Singh G, Fakharuzi NA, Balasubramanian $S$, Swamynathan P, Thej C, et al. Transplantation of human bone marrow mesenchymal stromal cells reduces liver fibrosis more effectively than Wharton's jelly mesenchymal stromal cells. Stem Cell Res Ther. 2017;8(1):143. https://doi.org/10.1186/ s13287-017-0595-1

PMid:28610623

22. Braga TT, Agudelo JS, Camara NO. Macrophages during the fibrotic process: M2 as friend and foe. Front Immunol. 2015;6:602. https://doi.org/10.3389/fimmu.2015.00602 PMid:26635814

23. Chaudhuri B, Pramanik K. Key aspects of the mesenchymal stem cells (MSCs) in tissue engineering for in vitro skeletal muscle regeneration. Biotechnol Mol Biol Rev. 2012;7(1):5-15.

24. Yang $\mathrm{H}$, Sun L, Pang $\mathrm{Y}, \mathrm{Hu} \mathrm{D}, \mathrm{Xu} \mathrm{H}$, Mao S, et al. Threedimensional bioprinted hepatorganoids prolong survival of mice with liver failure. Gut. 2021;70(3):567-74. https://doi. org/10.1136/gutjnl-2019-319960

PMid:32434830

25. Michalopoulos GK, Khan Z. Liver regeneration, growth factors, and amphiregulin. Gastroenterology. 2005;128(2):503-6. https:// doi.org/10.1053/j.gastro.2004.12.039 PMid:15685562

26. Nelsen CJ, Rickheim DG, Timchenko NA, Stanley MW, Albrecht JH. Transient expression of cyclin D1 is sufficient to promote hepatocyte replication and liver growth in vivo. Cancer Res. 2001;61(23):8564-8.

PMid: 11731443

27. Kuramitsu K, Sverdlov DY, Liu SB, Csizmadia E, Burkly L, Schuppan $\mathrm{D}$, et al. Failure of fibrotic liver regeneration in mice is linked to a severe fibrogenic response driven by hepatic progenitor cell activation. Am J Pathol. 2013;183(1):182-94. https://doi.org/10.1016/j.ajpath.2013.03.018

\section{PMid:23680654}

28. Katoonizadeh A, Nevens F, Verslype C, Pirenne J, Roskams T. Liver regeneration in acute severe liver impairment: A clinicopathological correlation study. Liver Int. 2006;26(10):1225-33. https://doi. org/10.1111/j.1478-3231.2006.01377.x PMid:17105588 